\title{
A comunidade imaginada "Irlanda": crenças de duas professoras de inglês em pré-serviço
}

\author{
The imagined community "Ireland": two pre-service \\ English teachers' beliefs
}

\author{
Tatiana Diello Borges \\ Universidade Federal de Goiás
}

\begin{abstract}
This paper presents some of the results of a Master's dissertation that investigated (1) the beliefs held by two pre-service English teachers about English speakers and their cultures and (2) how these teachers justify such beliefs. The theoretical framework was based on beliefs and identity, also taking into account the issue of imagined communities, in the field of language teaching/learning. The following data collection instruments were used: questionnaires, interviews, class observations, and group discussion. The results obtained suggest how important it is to seriously engage both language learners and teachers' beliefs about their imagined communities, as these can encourage or hinder students and teachers' investment in the language teaching/learning process.
\end{abstract}

Keywords

Beliefs about English teaching/learning; Imagined communities; Teacher instruction. 


\section{Resumo}

Neste artigo apresentamos parte dos resultados de uma pesquisa de mestrado, na qual se investigaram (1) as crenças de duas professoras de inglês acerca de falantes de língua inglesa e de suas culturas e (2) como elas as justificam. O referencial teórico constituiu-se de estudos sobre crenças e identidade, considerando também a questão das comunidades imaginadas, no processo de ensino/aprendizagem de línguas. Os instrumentos empregados foram: questionário, entrevista, observações de aulas e grupo de discussão. Sucintamente, os resultados apontam para a relevância de considerarmos seriamente as crenças de alunos e professores de línguas sobre suas comunidades imaginadas, já que estas são capazes de estimular ou não o investimento durante o processo de ensino/aprendizagem.

\section{Palavras-chave}

Crenças sobre ensino/aprendizagem de inglês; Comunidades imaginadas; Formação de professores. 


\section{Introdução}

$\mathrm{U}$

m tema central de estudos na área de formação de professores vem sendo a investigação de crenças (BARCELOS, 2004), pois é através da compreensão destas que poderemos entender a prática do professor. De acordo com Pintrich (1990) apud Pajares (1992, p. 307-308), "[...] as crenças são os instrumentos psicológicos mais valorosos que se pode ter na construção da formação do professor". ' Como lembram Freeman e Johnson (1998), os docentes são pessoas que entram em programas de formação de professor com experiências anteriores, valores pessoais e crenças que compõem seu conhecimento sobre ensino e orientam o que realizam em sala de aula. Muito do que sabem vem de suas lembranças como aprendizes de língua. De acordo com Kennedy (1991, p. 2) apud Freeman e Johnson (1998, p. 401), "os professores, como outros aprendizes, interpretam novos conteúdos através de seus conhecimentos anteriores e modificam e reinterpretam novas idéias com base naquilo que já conhecem e acreditam".

Nesse sentido, considerando a relevância da investigação das crenças para uma melhor compreensão do processo de ensino/aprendizagem de línguas (PAJARES, 1992; JOHNSON, 1994; FREEMAN e JOHNSON, 1998; BARCELOS, 2000, 2001), este estudo teve como propósito pesquisar quais são as crenças que professores de língua inglesa em pré-serviço possuem em relação aos falantes desse idioma e de suas respectivas culturas.

Dependendo das crenças - diversas vezes fundamentadas em estereótipos - que os alunos/professores possuem sobre a cultura estrangeira, argumenta Brun (2004), a identificação cultural será mais ou menos capaz de promover um sentimento de pertencimento e de participação efetiva. A autora afirma também que "na aprendizagem de línguas a identificação com o nativo, a língua ou o locutor bilíngüe é considerada como uma condição de sucesso (ou ao menos uma atitude favorável)"(BRUN, 2004, p.92). 
Assentindo com essas observações, Sade (2003, p. 59) argumenta que "se os alunos se identificarem positivamente com o grupo de falantes em questão, estarão mais motivados a aprender [...] para fazerem parte do grupo. No entanto, se essa identificação for negativa, o aprendiz não estará receptivo a aprender a língua".

Jakobovits (1970), Tílio (1981), Barata (1999) também corroboram a argumentação de Brun (2004) e Sade (2003) ao asseverar que aprendizes com atitudes favoráveis em relação à cultura e ao povo da língua estrangeira estudada apresentam maiores chances de serem bem-sucedidos no processo de aprendizagem.

Ponderando a respeito dessas afirmações e suas implicações para o processo de ensino/aprendizagem de línguas estrangeiras, procuramos, nesta pesquisa, identificar e analisar as crenças que duas professoras de inglês em préserviço possuem em relação aos falantes de língua inglesa e de suas respectivas culturas e tentar compreender como essas crenças são justificadas por elas. Esses objetivos partem da pressuposição de que o aluno/professor, ao entrar em contato com a língua estrangeira e, simultaneamente, ao adquirir conhecimentos socioculturais acerca da comunidade que a utiliza, é, de certo modo, obrigado a se renovar não só lingüisticamente, mas, sobretudo, culturalmente.

Com o propósito de facilitar a tarefa do leitor, apresentamos a seguir a organização deste artigo. Na primeira parte, apresentamos o referencial teórico da pesquisa, na qual tratamos dos construtos crenças e comunidades imaginadas (imagined communities) no campo de ensino/aprendizagem de línguas. $\mathrm{Na}$ segunda seção, trazemos a metodologia escolhida para a realização do estudo, detalhando sua natureza, o contexto investigado, as participantes, os instrumentos empregados na coleta de dados e a análise dos resultados. Na terceira parte, analisamos e discutimos alguns resultados finais obtidos. Por fim, apresentamos algumas implicações pedagógicas e sugestões para futuras pesquisas que objetivem investigar crenças sobre ensino/aprendizagem de língua inglesa.

\section{Referencial teórico}

Este estudo apoiou-se em trabalhos da área de ensino/aprendizagem de línguas estrangeiras que tiveram como foco de investigação a questão das crenças e da identidade, considerando também a questão das comunidades imaginadas (imagined communities), ao longo do processo de ensinar/aprender línguas. 
No que se refere ao construto crenças, observa-se que não há ainda uma única definição para esse conceito em Lingüística Aplicada. O termo é alvo de várias denominações, tais como, "[...] atitudes, opiniões, percepções, concepções, teorias implícitas, teorias explícitas, teorias pessoais [...]" (PAJARES, 1992, p. 309) e essa diversidade é um dos motivos que torna esse construto tão complexo de ser investigado (PAJARES, 1992; WILLIAMS e BURDEN, 1997; SILVA, 2000; BARCELOS, 2001, 2004).

Para o contexto desta pesquisa, entendemos crenças como as idéias que tanto alunos quanto professores de inglês possuem em relação a falantes de língua inglesa e de suas respectivas culturas. Essas idéias compartilhadas modelam os processos e as estratégias que esses indivíduos desenvolvem e implementam ao aprender e utilizar a língua estudada/ensinada (CASTELLOTTI e MOORE, 2002). Vale destacar que essas imagens podem ser baseadas tanto em experiências de fato vivenciadas por aprendizes e professores quanto em estereótipos e preconceitos que emergem e são perpetuados na sociedade através de vários meios, como a mídia e a literatura, entre outros.

Considerando que este estudo procurou investigar crenças acerca de um aspecto mais específico do processo de ensino/aprendizagem de línguas - os falantes de língua inglesa e suas culturas -, ocupamo-nos, a seguir, dessas crenças específicas. ${ }^{2}$

É de fácil constatação que grande parte dos trabalhos que se ocupam da investigação de crenças sobre ensino/aprendizagem de língua estrangeira se concentra apenas em aspectos gerais do processo de se ensinar/aprender línguas.

Entretanto, esse foco de investigação sobre crenças parece estar mudando. Nos últimos sete anos, pôde-se perceber um aumento significativo de dissertações ${ }^{3}$ desenvolvidas nos programas de pós-graduação brasileiros que procuraram estudar crenças específicas relacionadas ao ensino/aprendizagem de línguas estrangeiras (SILVA, 2000; CARAZZAI, 2002; ARAÚJO, 2004; BELAM, 2004; FINARDI, 2004; SILVA, 2004; LIMA, 2005; MORAES, 2005; VECHETINI, 2005; BASSETTI, 2006; PITELI, 2006; BORGES, 2007).

Os resultados obtidos no levantamento realizado por Borges, Paula Fernandes e Barcelos (2007) também vêm comprovar essa expansão. No tocante aos resultados referentes ao foco dos estudos, constatou-se que, embora a maioria dos trabalhos apresentados tenha ainda se ocupado de crenças sobre ensino/ aprendizagem em geral, algumas pesquisas já começaram a tratar da investigação 
de crenças mais específicas. Crenças sobre avaliação, bom aprendiz, correção de erros, fonologia, gramática e leitura foram o foco desses trabalhos.

Barcelos (2004), que já apontava para a carência de estudos mais profundos que focalizem crenças mais específicas, também observa o modesto, embora cada vez mais crescente, interesse acerca da investigação de crenças mais específicas ao elencar alguns estudos que têm pesquisado essas crenças sobre vários aspectos: "gramática (BORG, 1998; CARAZZAI, 2002; DUTRA e MELLO, 2004), leitura (Graden, 1996 $6^{4}$ ), bom professor (Silva, 2000), bom aprendiz (ARAÚJO, 2004), correção de erros (S. SILVA, 2004), ${ }^{5}$, linguagem lúdica (FINARDI, 2004), tradução (Pagano, 2000), vocabulário e ensino de vocabulário (CONCEIÇÃO, 2004; VECHETINI, 2005), motivação (LIMA, 2005), avaliação (ROLIM, 1998; BELAM, 2004, MORAES, 2005) e oralidade (V. SILVA, 2004)" (BARCELOS, 2006, p. 23 - grifos nossos). Conforme a autora, "esses estudos contribuem para uma compreensão mais detalhada a respeito de fatores específicos dentro do processo de aprendizagem/ensino de línguas e da relação desses fatores com crenças" (BARCELOS, 2006, p. 23).

A seguir, apresentamos nosso recorte na questão da identidade, no qual tratamos das comunidades imaginadas (imagined communities) de professores e alunos de línguas, as quais se apresentaram de modo muito evidente nos resultados desta pesquisa.

Alguns pesquisadores interessados no processo de aprendizagem de línguas se apropriaram do termo comunidades imaginadas, originalmente cunhado por Anderson (1991) apud Kanno e Norton (2003, p. 241), na tentativa de compreender um pouco melhor esse complexo processo (MURPHEY, 1998; NORTON, 2000, 2001; BLACKLEDGE, 2003; DAGENAIS, 2003; KANNO, 2003; KANNO e NORTON, 2003; NORTON e KAMAL, 2003; PAVLENKO, 2003; SILBERSTEIN, 2003; MURPHEY, JIN e LI-CHI, 2004, PAVLENKO e NORTON, no prelo). Segundo esses autores, uma característica das comunidades imaginadas de fundamental importância para esse maior entendimento é que elas são capazes de estimular um investimento ${ }^{6}$ (ou não) ao longo do aprendizado.

Assim, entendemos que esse aspecto inerente às comunidades imaginadas seja a base deste estudo, pois, dependendo de quais são as crenças que alunos, no caso em questão, alunos-professores, de línguas possuem em relação a suas próprias comunidades haverá ou não uma identificação com estas - incluindo, naturalmente, os povos e as culturas pertencentes a essas comunidades $-\mathrm{e}$, 
conseqüentemente, um maior ou menor estímulo para investir ou não no processo de ensino/aprendizagem.

Nos parágrafos seguintes, apresentamos o estudo de Murphey, Jin e LiChi (2004), no qual a questão das comunidades imaginadas foi contemplada.

Por meio da análise de narrativas a respeito da aprendizagem de línguas de 84 alunos japoneses e de 58 tailandeses Murphey, Jin e Li-Chi (2004) buscaram compreender melhor como se dá a construção social das identidades desses aprendizes e de suas comunidades imaginadas.

A argumentação dos autores baseia-se no fato de que os aprendizes precisam ter experiências prósperas de aprendizagem de línguas para que estas possam originar um desejo de se identificarem com certos grupos, posicioná-los em comunidades imaginadas e estimulá-los a se perceberem como usuários bem-sucedidos de segunda língua.

Pela análise dos dados, Murphey, Jin e Li-Chi (2004) puderam perceber momentos em que os alunos não possuíam comunidades imaginadas para se identificar e, conseqüentemente, investir na aprendizagem, momentos de nãoidentificação com suas comunidades - como lembram os autores, algumas vezes, nossas comunidades imaginadas não são exatamente o que imaginávamos -e ainda ocasiões em que comunidades imaginadas que já existiam antes do início da aprendizagem em língua inglesa se modificaram, enfraqueceram ou foram esquecidas.

Refletindo sobre esses três momentos distintos observados nas narrativas dos alunos, Murphey, Jin e Li-Chi (2004) finalizam o artigo afirmando que as comunidades imaginadas que os alunos possuem não devem se ignoradas ao longo do processo de aprendizagem, pois, como visto, são capazes de incentivar ou não um investimento nesta. Ainda para os autores, após a leitura dessas histórias de aprendizagem, os professores poderiam acompanhar de modo mais eficiente cada um de seus alunos, pois, com essas informações, as chances de saberem como poderiam adaptar sua prática pedagógica para torná-la, de fato, centrada no aluno, seriam maiores. Para Murphey, Jin e Li-Chi (2004), é imprescindível que os docentes permitam a seus aprendizes participarem integralmente do processo de aprendizado, e uma das maneiras de se fazer isso, de acordo com os autores, é dar lugar para que os alunos, juntamente com suas identidades, comunidades imaginadas e seu desenvolvimento, sejam o tópico principal dos cursos ministrados pelos professores. 
Sucintamente, é possível observar que os estudos que se ocupam da questão das comunidades imaginadas no campo de ensino/aprendizagem de línguas estrangeiras demonstram a importância de se considerá-las seriamente, pois uma das características mais relevantes das comunidades imaginadas para essa área da Lingüística Aplicada refere-se ao fato de que são capazes de estimular ou não um investimento ao longo do processo de se aprender/ensinar línguas.

\section{Metodologia}

Nesta pesquisa, de natureza qualitativa, utilizamos o estudo de caso para tentar analisar a relação existente entre crenças e identificação cultural no processo de ensino/aprendizagem de professores de inglês em pré-serviço. Para isso, dois objetivos mais específicos foram elaborados, nos quais procuramos (1) identificar e analisar as crenças que duas professoras de língua inglesa em préserviço possuem em relação aos falantes de inglês e de suas respectivas culturas e (2) tentar compreender como essas crenças são justificadas por elas.

A pesquisa foi realizada em um Centro de Extensão de uma universidade pública da região Sudeste do Brasil. Esse Centro, com 30 anos de existência, oferece cursos de línguas estrangeiras (inglês, espanhol, italiano, alemão, francês, português como língua estrangeira) para professores, funcionários e alunos da universidade e também para a comunidade em geral. O Centro de Extensão conta com um acervo de materiais didáticos e uma videoteca, que são utilizados tanto por alunos quanto professores.

Júlia e Bete, nomes escolhidos pelas professoras, foram as participantes deste estudo. São alunas do curso de Letras (Inglês) e ministram aulas de língua inglesa no Centro de Extensão citado anteriormente. Uma delas tem um ano e meio de experiência no ensino deste idioma e a outra tem dois anos.

Questionário, entrevista individual, observações de aulas, gravadas em áudio e acompanhadas de anotações de campo, e um grupo de discussão, envolvendo as professoras participantes e a pesquisadora foram os instrumentos utilizados nesta pesquisa.

O questionário, do tipo aberto e ministrado no início da pesquisa, foi dividido em duas partes. Na primeira, com onze questões, procuramos, basicamente, obter informações a respeito da vida acadêmica e profissional das participantes. Na segunda, com sete perguntas, tínhamos um objetivo específico: detectar as 
crenças das professoras em pré-serviço em relação a falantes de inglês, aos países falantes desta língua e às respectivas culturas desses povos. Tendo em mente a questão da identificação, ou não-identificação, com a língua, o país, os falantes ou a cultura do idioma estrangeiro aprendido/ensinado, procuramos verificar também se, para as participantes, existe uma relação entre estudar uma língua estrangeira, no caso o inglês, e se identificar com a cultura dessa língua (Pergunta 7).

As entrevistas utilizadas foram semi-estruturadas, elaboradas com base nas respostas obtidas no questionário, nas observações das aulas e nas notas tomadas ao longo dessas observações e gravadas em áudio. O objetivo da utilização desse instrumento foi detectar as crenças das professoras e clarificar as afirmativas feitas por elas no questionário.

As observações de aulas, gravadas em áudio e acompanhadas de anotações de campo, ocorreram durante os meses de abril a junho de 2006. Ao todo 22 aulas das duas participantes foram observadas. Os propósitos dessas observações foram: a) comparar dados dos questionários e das entrevistas com as ações; e, b) servir como outra fonte para a triangulação de dados.

Por último, utilizamos um grupo de discussão formado pelas duas professoras e a pesquisadora. Tínhamos os seguintes objetivos com esse procedimento: a) conversar sobre as crenças mais comuns das docentes em relação ao tema dessa pesquisa e sobre as justificativas que elas apresentaram para essas crenças; e, b) abrir um espaço para que pudessem refletir a respeito da influência dessas crenças ao longo do processo de ensino/aprendizagem de línguas. Os assuntos abordados nesse grupo foram elaborados tendo como base principal as entrevistas realizadas, mas também foram consideradas as afirmativas feitas pelas professoras no questionário e as aulas observadas. A conversa, gravada em áudio, teve a duração de 40 minutos.

A análise dos dados desta pesquisa adotou os procedimentos da pesquisa qualitativa. Primeiramente, realizamos uma leitura geral dos dados a fim de obter categorias. Em segundo lugar, procedemos a uma leitura minuciosa, anotando nossas impressões, com o propósito de incitar questionamentos e procurar conexões entre as partes. Por último, por meio dessa triangulação, conseguimos agrupar os dados em três grandes blocos de análise. Esses blocos, constituídos por temas que surgiram de modo freqüente e muito significativo nos dados de ambas as professoras participantes desta pesquisa, foram os eixos de sustentação do capítulo de Análise dos Dados deste estudo. 
Neste artigo, por questões de espaço, escolhemos apresentar os resultados de apenas um dos temas recorrentes.

\section{Análise e discussão dos resultados}

Neste bloco de análise dos dados apresentamos as crenças que as professoras participantes possuem a respeito dos irlandeses e de sua cultura, assim como suas justificativas para essas crenças.

Em relação ao povo irlandês, Júlia demonstra uma considerável apreciação. Segundo ela, os irlandeses são "carismáticos" $(\mathbf{Q}, \mathbf{1 6} / \mathbf{0 5} / \mathbf{0 6})$, "muito alegres" (E, 25/05/06) e "com uma base cultural fascinante" (Q, 16/05/06).

Essas crenças são justificadas pela professora em função de influências do vocalista Bono do U2 - grupo de rock irlandês -, de bandas irlandesas - como Boyzone e West Life -, de leituras, filmes e estereótipos.

O seguinte excerto ilustra as crenças e justificativas apresentadas acima:

P. Essa parte da Irlanda, você fala que acha que os irlandeses são carismáticos, né?! Por que você acha isso?

J: O Bono uma vez, falou, achei muito bom ele ter falado, que os irlandeses são brasileiros europeus [...] Eu adorei quando ele falou isso! [...] por causa que lá eles [...] gostam muito de futebol [...] Cerveja. Essas coisas assim. Então, é um povo muito alegre [...] Eu acho que eles são alegres. Só não têm, assim, a coisa caliente, né?! Eu acho que não é nem caliente, é coisa de latino mesmo [...] É, da Europa inteira [...] Do hemisfério norte todo eu acho que eles são os mais, assim, só precisava o sangue latino pra ser mais carismático.

P. Entendi. [...] E [...] você tem essa imagem por meio de leituras?

J: Leitura., ah, música também, U2 [...] Boy band. Tem essas boy band de lá que eu gosto: Boyzone, West Life [...] É, acho que vem da música. Ah, deve tersido algum filme que eu vi também. (E, 25/05/06).

Bete, por sua vez, considera os irlandeses descontraídos, "jogados" (E, 30/05/06) - no sentido de espontâneos - receptivos, acolhedores, amigos, abertos e apreciadores de bebidas alcoólicas. Para ela, eles são parecidos, em parte, com o povo brasileiro. As crenças da participante são justificadas em 
virtude de uma disciplina que cursou chamada Literatura Irlandesa, de um conhecido que morou na Irlanda, de estereótipos e de professores e colegas que já foram para esse país.

Essas crenças e justificativas podem ser observadas nos excertos abaixo:

B: [...] São muito jogados, que é o meu estilo!

P. [...] você já conheceu algum irlandês?

B: [...] não. Mas eu ouço falar muita coisa. [...] Muita coisa pela internet que a gente tem que tá pesquisando [para a disciplina Literatura Irlandesa] sobre o contexto, sobre o país [...] aí, eu acabo descobrindo muita coisa, né [...] dá pra ouvir muita coisa [...] dos professores [...] de outros colegas. (E, 30/05/06).

B: Tem um amigo de uma amiga minha que tá voltando agora [...] Ele falou que a recepção [...] foi muito boa, o pessoal acolhe todo mundo muito bem. [...] eu acho que tem muito dessa coisa de brasileiro, né? [...] o brasileiro [...] Gosta muito de chegar, beijar, abraçar. Cumprimentar de mão [...] E tem essa coisa muito da proximidade, né? [...] eu imagino que seja uma coisa amiga, que eles sejam um pouco mais abertos, mas não tanto como brasileiro. (E, 30/05/06).

Pensando em cultura irlandesa, propriamente, percebe-se também que as professoras, assim como em relação ao povo irlandês, são grandes simpatizantes. De acordo com Júlia, essa cultura pode ser definida como "fascinante" $(\mathbf{Q}, \mathbf{1 6} / \mathbf{0 5} / \mathbf{0 6})$ e "linda" (E, 25/05/06). A participante também entende a cultura irlandesa em termos de produção literária, cinematográfica e musical, como podemos observar no seguinte excerto:

J: [...] a cultura da Irlanda é uma coisa linda!

P: Quando você pensa na cultura irlandesa, que você pensa?

J: Penso em literatura [...] Joyce [...] e no cinema também, né?! [...] Depois vem música também. (E, 25/05/06).

Suas justificativas para essas crenças são as mesmas mencionadas a respeito dos irlandeses, incluindo aqui seu conhecimento acerca da literatura irlandesa. Sobre esse último aspecto, gostaríamos de registrar que esse conhecimento, de acordo com Júlia, foi todo construído por conta própria, não 
tendo cursado nenhuma literatura irlandesa durante seu curso de Letras. Acreditamos que esse fato demonstre muito bem o interesse, a identificação que possui em relação à Irlanda, seu povo e cultura.

"Bebida!" (E, 30/05/06), “muita" (E, 30/05/06) bebida! Essa é a primeira imagem que Bete tem ao pensar em cultura irlandesa. A professora acredita também que seja uma cultura "bem legal" (E, 30/05/06) e "muito alegre" (E, 30/05/06). Suas justificativas para essas crenças, assim como ocorre com Júlia, também são as mesmas que apresenta para os irlandeses:

B: $[. .$.$] a cultura da Irlanda [...] eu acho bem legal.$

P. Então, quando você pensa em cultura irlandesa, qual que é a primeira imagem/ representação que você tem?

B: Bebida! [...] Muita! Mas é! [...] todos os professores eles passam isso pra gente! (E, 30/05/06).

B: [...] eu acho que [...] é uma coisa muito alegre. Tudo gira em torno de dança, de festa, de bebida, de comemoração. É um país, assim, nossa, eu vou te dar um exemplo tosco, mas o Bono Vox, o vocalista do U2. [...] Ele é um cara que [...] ama o Brasil! Por quê? Oh, o Brasil tem tudo a ver com a Irlanda nessa coisa de festa, de bebida, de comemorações. Então, isso é uma coisa que [...] eu tô estudando, né, mais de Joyce, O'Connor. [...] é mais antigo, mas não deixa de ser, essas tradições (E, 30/05/06).

P. E esse colega que você comentou que tá voltando [...] da Irlanda, ele confirma essas imagens que a gente tem, tipo da bebida?

B: Confirmou! Ele falou que [...] lá [...] pra tudo tem uma festa e a tradição de velórios é super engraçada porque a galera bebe o morto, mesmo! É igual ((inint)) aqui. (E, 30/05/06).

Um aspecto muito enfatizado por Bete que percebemos ao longo da entrevista foi sua identificação em relação à cultura irlandesa. Observamos que essa identificação ocorre, como a própria participante frisa muito bem em suas falas, devido ao fato de o estilo de vida, os hábitos e costumes dos irlandeses serem muito parecidos com os dela. Vale lembrar que essas crenças que a professora possui acerca do jeito de ser, do estilo de vida do povo irlandês foram construídas com base em depoimentos de colegas e professores que já estiveram na Irlanda, em estereótipos e em seus estudos na disciplina Literatura Irlandesa. 
Nunca, de fato, teve contato com irlandeses. Os seguintes excertos ilustram essa questão salientada pela participante:

B: [...] a Irlanda é um dos mais ((refere-se a países europeus)) que eu acho que eu me identifico mais pelo meu estilo de vida [...], por exemplo, [...] tem aquela diferença de homem e mulher, mulher não pode beber, homem pode, que eu acho um absurdo! ((risos)) E, por exemplo, [...] todos os funerais irlandeses, eu acho legal, ((inint)), vários tipos de coisa que eu tô aprendendo agora ((na disciplina Literatura Irlandesa)) que eu tô me identificando demais. [...] tem todo o contexto da Irlanda, essa coisa da religiosidade de lá tem umas que eu me identifico muito, essa coisa da briga, né, o protestante e o católico [...]. (E, 30/05/06).

P: $[\ldots]$ você fala $[\ldots]$ que $[\ldots]$ se identifica com os irlandeses e com a cultura [...] Principalmente em aspectos tradicionais da Irlanda ((refere-se a uma informação fornecida pela participante no questionário)).

B: É. Essa coisa mesmo de beber e [...] eu acho que é super interessante porque isso é muito brasileiro. O brasileiro tudo, tudo envolve isso também. Envolve festa, envolve música, envolve dançar, envolve comida. Eu acho muito parecido [...] Eu me identifico bastante [...]. (E, 30/05/06).

Uma outra questão que atraiu nossa atenção ao longo da análise das crenças de Bete sobre a cultura irlandesa foi a maneira que externou sua identificação. De acordo com nossa interpretação, notamos que suas afirmações a respeito dessa identificação eram feitas, na maioria das vezes, em oposição ao povo norte-americano. Em outras palavras, Bete parece simpatizar com a cultura da Irlanda por não se identificar com os norte-americanos.

Acreditamos que o seguinte excerto demonstre muito bem essa questão da oposição que percebemos nas falas de Bete:

P: $[. .$.$] lá no questionário [...] você afirma que simpatiza com a Irlanda [...]$ Porque se identifica mais com a cultura européia. Eu queria que você falasse um pouquinho mais dessa cultura européia.

B: Hum, hum. Na verdade, eu comecei a fazer agora um curso de literatura irlandesa e eu tô estudando vários autores que eles falam de muitas coisas interessantes. [...] o esquema da cultura lá, essa coisa da diferença do homem e da mulher, muita coisa ligada ao meu estilo de vida, às coisas que eu gosto. 
P: Aí, você se identificou de cara!

B: Eu me identifiquei mais porque [...] eu acho que eles ((refere-se aos norteamericanos)) são muito nacionalistas, é uma coisa muito brain wash mesmo, [...] eles repetem, eles repetem muito e [...] eu tenho um contato com alguns americanos e algumas coisas que alguns americanos falam, algumas visões [...] deles de mundo [...] é muito diferente do meu estilo [...] eu acho [...] (E, 30/05/06 - grifos nossos).

Observamos que Júlia também externa sua identificação em termos de oposição, com a diferença de que se refere aos havaianos e australianos e não aos irlandeses. Cabe lembrar aqui que o conceito clássico de identidade se sustenta sobre a idéia de oposição em relação ao outro, o que se reflete claramente nas falas de ambas as participantes.

Uma afirmativa, a nosso ver, muito representativa da identificação da professora com os havaianos e sua cultura, em oposição aos norte-americanos, é quando diz, em entrevista: "[...] eu gosto da cultura ((refere-se à cultura havaiana)) [...] o Havaí pra mim é uma cultura totalmente diferente da cultura americana". (E, 25/05/06 - grifos nossos).

De acordo com a participante, o povo havaianoé $100 \%$ não americano. Aliás, para Júlia, o Havaí é considerado um país e não um estado dos Estados Unidos. Em suas palavras: "[...] tem um país, que eu chamo de país, que é um estado dos Estados Unidos, o Havaí é um país! Diferente! [...]”. (E, 25/05/06 grifos nossos).

Assim, conforme afirma Júlia, ela não consegue imaginar um havaiano comendo cachorro-quente e trabalhando demasiadamente. Ainda, segundo a professora, os havaianos são mais tranqüilos e não possuem a mesma pressão ideológica ${ }^{7}$ que os norte-americanos. Essas crenças da participante são justificadas em função de leituras e filmes.

No tocante aos australianos, Júlia afirma que simpatiza com eles porque são pessoas que, de acordo com seu conhecimento histórico, não se encaixaram nos moldes ingleses e, portanto, foram exportadas para a Austrália. A participante afirma também que acredita que o povo australiano seja mais simpático que o inglês, apesar de, segundo ela, terem um sotaque parecido. Essa crença a respeito do povo australiano se justifica em decorrência de leituras realizadas.

Refletindo a respeito da nossa impressão de que as participantes se identificam com o povo/cultura irlandesa, havaiana e australiana por não 
simpatizarem com os norte-americanos, e com os ingleses, no caso de Júlia, supomos que isso seja uma outra maneira de as professoras expressarem uma certa resistência e antipatia que possuem em relação aos norte-americanos e ingleses. Gostaríamos de ressaltar que com essa suposição não estamos desconsiderando a possibilidade de Júlia e Bete se identificarem com os irlandeses, havaianos e australianos, e suas culturas, simplesmente porque os apreciam, acham interessante seus estilos de vida.

Nossa suposição baseia-se, primeiramente, nas crenças e na nãoidentificação de Júlia e Bete acerca dos norte-americanos apresentadas em um outro bloco de análise dos dados da dissertação e, em segundo lugar, por termos percebido, em vários momentos das entrevistas e das aulas observadas, a preocupação de ambas as professoras de tentar mostrar para seus alunos que a língua inglesa não é falada apenas nos Estados Unidos, acrescentaríamos ainda a Inglaterra, mas também em outros países.

No seguinte excerto, observamos, assim, que Bete acredita que seja relevante "quebrar esse conceito" (E, 30/05/06) de que os Estados Unidos e a Inglaterra sejam os únicos países falantes de inglês:

B: [...] tem muito aluno que não gosta dos Estados Unidos porque tem um estereótipo. mas, e também parece que acha que só nos Estados Unidos que tem inglês [...] Falou inglês falou nos Estados Unidos. Falou inglês falou Disney [...] tudo ser em volta dos Estados Unidos [...] tem até o projeto de uma menina que fez Prática de Ensino [...] era produção de material didático. Essa menina, ela fez um jogo em inglês que tinha todos os países, vários países de inglês como língua nacional e não tinha os Estados Unidos. Tinha Irlanda, tinha Austrália, tinha alguns países na África que têm inglês como língua nacional [...] quebra o conceito mesmo. Não tinha nem Estados Unidos nem Inglaterra [...] Então, quebra esse conceito mesmo de ser só os dois países de língua inglesa [...] eu gosto de dar cultura, dar outras culturas sem ser a cultura americana. [...] eu acho interessante você falar de outros países também porque não fica essa coisa de só os Estados Unidos como exemplo. (E, 30/05/06).

É interessante observar que, em uma de suas aulas, Bete utilizou um episódio do seriado Friends que, segundo ela, evidenciava a questão da diversidade. $\mathrm{O}$ episódio selecionado pela professora tinha como tema o Dia de Ação de Graças (Thanksgiving Day), data celebrada tanto nos Estados Unidos quanto no Canadá: 
B: [...] Na verdade, eu gosto muito de Friends e eu não queria fazer alguma coisa que tivesse só ligação com a cultura americana [...] Porque o Thanksgiving Day eles têm no Canadá também [...] Aí, [...] tinha, tem outros episódios também que tem essa coisa da cultura, mas era uma coisa muito, muito da norte-americana. (E, 30/05/06).

Ao analisarmos esse excerto, percebemos claramente que Bete, ao preparar essa atividade, teve a preocupação de não apresentar a seus alunos um aspecto cultural da língua inglesa que tivesse relação apenas com a cultura norteamericana, pois, de acordo com ela, "tem muito aluno que não gosta dos Estados Unidos" e "essa coisa da antipatia, do não gostar [...] acaba que barra a aprendizagem de língua estrangeira. Vira um bloqueio". (E, 30/05/06). Uma das professoras participantes da pesquisa de mestrado de Coelho (2005, p. 85) também relata que seus alunos não demonstravam interesse em aprender inglês "por acreditarem ser língua de americano".

A crença de que é válido mostrar para os alunos que existem outros países, além dos EUA e da Inglaterra, que têm o inglês como língua nacional também foi abordada no grupo de discussão realizado com as participantes e a pesquisadora.

Bete comenta que na Faculdade de Educação, na qual cursou algumas disciplinas relacionadas à didática de línguas estrangeiras, os docentes orientam os alunos-professores a "não ligar muito a uma coisa só((refere-se a países)), a variar" (GD, 07/07/06), ao ministrarem suas aulas.

Tanto Júlia quanto Bete observam ainda que esse discurso sobre o fato de que existem outras nações falantes de inglês, além dos Estados Unidos e da Inglaterra, também se encontra presente na Faculdade de Letras. As professoras comentam que isso pode ser percebido mais nitidamente nas disciplinas de Literatura:

J: [...] esse plus que tem [...] inglês em outros lugares eu acho que acontece na literatura.

B: É [...] eu tenho feito literaturas que não são voltadas pra norte-americana e nem pra inglesa. como literatura do Caribe, literatura irlandesa.

J: É. Tem a literatura de minoria. (GD, 07/07/06).

Em um levantamento realizado por nós junto ao Colegiado de Graduação da Faculdade de Letras, também pudemos constatar a presença desse discurso nas disciplinas destinadas ao ensino de Literatura em Língua Inglesa. Nesse 
levantamento, procuramos examinar quantas disciplinas de Literatura em Língua Inglesa, oferecidas nos anos de 2005 e 2006, abordavam a literatura de outros países, além dos EUA e da Inglaterra. As Literaturas Canadense, Irlandesa, Caribenha e Indiana estavam presentes na grade como temas a serem contemplados ao longo dos semestres de 2005 e 2006.

Essa crença de que é relevante apresentar para os alunos que há outras nações falantes de língua inglesa também pôde ser percebida tanto na fala quanto na ação da outra professora. Assim como Bete, Júlia comenta que em vários momentos tem a impressão de que "os alunos já têm na cabeça que quem fala inglês é só Estados Unidos e Inglaterra" (E, 25/05/06).

Quando indagada, em entrevista, se acredita que seja relevante apresentar para seus alunos que há outros países que falam a língua inglesa, Júlia responde que sim e exemplifica como tenta fazer isso em sala de aula:

J: Eu acho legal. Por isso que eu falo [...] eu sempre falo quando eu ensino os países, eu faço um mapinha, pseudomapinha, né? Eu faço um mapinha e falo: a Europa é aqui, tá, eu vou mostrar pra vocês onde é que é isso daqui, que é o United Kingdom, aí eu explico, explico pra eles o que é United Kingdom, o queé País de Gales, o que é Escócia e o que é Irlanda do Norte e o que é República da Irlanda. (E, 25/05/06).

Em sala, essa crença de Júlia pôde ser observada nas músicas que escolhe para seus alunos, pois tenta "diversificar o máximo" (E, 25/05/06), levando não apenas bandas dos Estados Unidos ou da Inglaterra, mas também de outros países que igualmente têm o inglês como língua materna. Em entrevista, ela explica:

J: Levar o U2 que é da Irlanda que é uma coisa que é mega conhecida, mas ninguém sabe que eles são da Irlanda. Se você chegar pra uma pessoa na rua e falar assim: sabe quem é o U2? Sei. Sei quem é o U2. De onde é que eles são? Eles são dos Estados Unidos. Eles não são. Eles são da Irlanda. Aí eu levanto isso pra eles ((para os alunos)) [...] Levar a Alanis que é do Canadá.

P. Ah, tá. Então de vários países que falam inglês (E, 25/05/06).

Júlia comenta ainda que fica "muito feliz!" (E, 25/05/06) quando seus alunos reconhecem seu esforço de tentar desmistificar, por meio da música, que o inglês seja falado somente por norte-americanos e ingleses. No excerto a seguir podemos observar esse contentamento: 
J: [...] Aquele dia que o C. ((refere-se a um de seus alunos)) soltou assim: ela é canadense ((refere-se à cantora Alanis Morrissette)), eu fiquei tão feliz! ((risos)). Sabe, o Canadá também é um país! Existe! E fala inglês! E tem gente famosa de lá! Igual o U2 da Irlanda! Eu fico muito feliz! (E, 25/05/06).

Tendo em mente as afirmações de Júlia e Bete, podemos inferir que um possível motivo para o fato de enfatizarem a diversidade de países falantes de inglês esteja relacionado à questão de não simpatizarem com os Estados Unidos e com os norte-americanos. Assim, em suas falas e aulas, essa diversidade se apresenta como um tópico fundamental.

Através da análise dos dados desse bloco, foi possível constatar, primeiramente, que Júlia e Bete possuem crenças semelhantes quanto aos irlandeses e à cultura da Irlanda. Sucintamente, acreditam que os irlandeses sejam carismáticos e alegres e que sua cultura seja fascinante e muito próxima de seus próprios estilos de vida. Em segundo lugar, ambas as professoras também apresentam justificativas muito similares. De modo geral, justificam suas crenças com base em estereótipos seus e de professores e colegas que já visitaram a Irlanda e em leituras realizadas, seja para disciplinas que cursam na universidade, seja por interesse próprio. Em terceiro lugar, percebemos que, opostamente ao que ocorre em relação aos Estados Unidos, ambas as professoras não distinguem o povo irlandês de sua cultura. Ao contrário, elas os entendem como uma entidade única. Em outras palavras, Júlia e Bete, conforme nossa interpretação, não concebem os irlandeses e sua cultura como algo fragmentado, no qual seja necessário selecionar as partes boas, assim como fazem em relação à cultura norte-americana ao escolher a literatura, o cinema e a música; mas, sim, como um bloco homogêneo, no qual tanto o povo quanto a cultura da Irlanda parecem ser constituídos apenas por aspectos positivos, como observamos nas falas das participantes.

Por último, notamos que a análise dessas crenças parece nos indicar que há, por parte de Júlia e Bete, uma identificação plena, já que simpatizam tanto com os irlandeses quanto com sua cultura.

Cogitamos que essa identificação por completo ocorra, de acordo com nosso entendimento, em decorrência do fato de Júlia e Bete sentirem pela Irlanda, ao contrário do sentimento que experimentam em relação aos Estados Unidos, uma espécie de bem-estar e conforto quanto a essa nação, ou, melhor colocando, quanto a essa comunidade imaginada. 
Conforme nosso entendimento, o conforto que as professoras experimentam em relação à comunidade imaginada "Irlanda" se explica em função do fato de acreditarem que essa comunidade, em vários aspectos, é muito semelhante ao Brasil, sua terra natal. Daí, a nosso ver, a ênfase de ambas as participantes na questão da Irlanda como um Brasil europeu. Como diria Bete: "Oh, o Brasil tem tudo a ver com a Irlanda!” (E, 30/05/06).

Assim, por imaginarem que o estilo de vida irlandês seja muito próximo de seus próprios e que os irlandeses sejam parecidos com os brasileiros, no sentido de que são carismáticos e acolhedores, as professoras conseguem se inserir nessa comunidade imaginada e participar dela. Em outras palavras, "vêem"-se, imaginam-se fazendo parte dela, seja no futuro, seja apenas em sonho.

Percebemos também nos relatos de Júlia e Bete, exatamente em razão do fato de imaginarem que brasileiros e irlandeses sejam muito semelhantes no jeito de ser e de perceber a vida, a crença de que suas identidades nacionais serão reconhecidas e preservadas nessa comunidade imaginada "Irlanda", opostamente ao que pensam que aconteceria no país administrado por George W. Bush.

Como Júlia declara muito bem: nos "Estados Unidos você não é uma pessoa, você é um latino! Você é um rótulo lâ" (E, 25/05/06). Nesse sentido, enfatiza que "[...] não quer viver o American Dream, [...] quer viver o Irish Dream!" (GD, 07/07/06 - grifos nossos).

Refletindo sobre os relatos de Júlia e Bete acerca de sua comunidade imaginada "Irlanda", percebemos a relevância de se considerar seriamente a questão do pertencimento, tanto de alunos quanto de professores, a uma comunidade imaginada ao longo do processo de ensino/aprendizagem de línguas. No caso das participantes deste estudo, foi possível observar que, devido a esse pertencimento à comunidade imaginada "Irlanda", Júlia e Bete conseguiram se legitimar, se tranquiilizar como aprendizes, professoras e falantes de inglês, já que não conseguem se sentir integralmente partes de uma comunidade imaginada que se formaria em torno de países como os Estados Unidos ou Inglaterra.

Assim, acreditamos que esse pertencimento de ambas as professoras possa facilitar consideravelmente seus investimentos na continuidade do aprendizado e ensino em língua inglesa. 


\section{Implicações e sugestões para futuras investigações}

Nesta seção, expomos, primeiramente, algumas implicações dos resultados obtidos neste estudo para o ensino/aprendizagem de inglês e, logo após, algumas sugestões para pesquisas futuras que objetivem investigar crenças a respeito do processo de ensino/aprendizagem de língua inglesa.

No que se refere às implicações, em primeiro lugar, e, talvez, primordialmente, este estudo demonstra, por parte dos professores, a necessidade de conscientização (ou manutenção dessa consciência, caso já exista) da relevância de se interessarem pelas crenças que seus alunos possuem em relação às suas comunidades imaginadas. A nosso ver, os docentes deveriam procurar se empenhar em desvendar quais são as crenças que seus aprendizes trazem para dentro das salas de aulas a respeito dos falantes da língua que estão aprendendo, do (s) país (es) onde esse idioma é falado, da (s) cultura (s) dessa (s) nação (ões). Acreditamos que, com esse tipo de atitude, os professores teriam maiores chances de compreenderem o porquê de alguns de seus alunos investirem no processo de aprendizagem e outros não.

Em segundo lugar, esta pesquisa evidencia a importância de os docentes, além de procurarem conhecer as crenças de seus alunos sobre as comunidades imaginadas, esforçarem-se também para identificar as próprias crenças que possuem em relação às suas comunidades. Cremos que esse autoconhecimento possa amenizar possíveis conflitos, desencontros entre suas representações e a de seus alunos em relação a um mesmo país ou, melhor colocando, a uma mesma comunidade imaginada.

Por fim, este trabalho explicita a necessidade de os professores - não só de inglês, mas todos, de modo geral - procurarem não reproduzir em sala, nem em conversas informais, idéias pré-concebidas a respeito do (s) país (es) onde a língua estudada é falada, assim como do (s) falante (s) e de sua (s) cultura (s). Como vimos, boa parte das crenças reveladas neste estudo se fundamentam em estereótipos que se perpetuam através de vários meios, como a mídia, as disciplinas de Literatura, os professores, entre outros.

No tocante às sugestões para estudos vindouros a respeito de crenças mais específicas sobre o processo de ensino/aprendizagem de inglês, em particular no que se refere à relação entre crenças e país (es), povo (s) e/ou cultura (s) dessa língua, apontamos quatro: 
(1) Investigações com professores em pré-serviço de outros Centros de Extensão para refutarem ou corroborarem os resultados deste estudo;

(2) Pesquisas com docentes em serviço, e também com alunos, a respeito do tema investigado no presente trabalho;

(3) Comparações entre as crenças dos aprendizes e dos professores sobre o(s) país(es), o(s) falantes e/ou a(s) cultura(s) da língua inglesa;

(4) Estudos que possibilitem, tanto aos docentes quanto aos alunos, a reflexão de suas crenças sobre o tema da presente pesquisa e como estas podem influenciar seus investimentos ao longo do processo de ensino/aprendizagem de inglês.

Esperamos que os resultados parciais desta pesquisa, apresentados neste artigo, possam, de alguma forma, contribuir para um maior entendimento da forte relação existente entre crenças e comunidades imaginadas de alunos e professores de línguas e da questão de que essa relação, de fato, encontra-se presente ao longo de todo o processo de ensino/aprendizagem, seja estimulando, seja desmotivando essa caminhada.

\section{Notas}

${ }^{1}$ Todas as traduções foram feitas pela autora do artigo.

${ }^{2}$ Segundo Barcelos (2007, p. 27), "pode-se dizer que a pesquisa sobre crenças no Brasil está dividida cronologicamente em três períodos, a saber: período inicial, de 1990 a 1995; período de desenvolvimento e consolidação, de 1996 a 2001 ; e o período de expansão, de 2002 até o presente". Quanto ao período de expansão, no qual esta pesquisa se insere por razões cronológicas e do tópico investigado, a autora afirma que "uma característica marcante dos estudos desse período diz respeito ao aumento da investigação de crenças mais específicas" (BARCELOS, 2007, p. 37 - grifo nosso).

${ }^{3}$ Embora prevaleça a elaboração de dissertações sobre o tema, ressaltamos que, de acordo com nosso conhecimento e até o momento da preparação deste artigo, três teses também foram desenvolvidas a respeito de crenças específicas: Conceição (2004), Madeira (2006) e Barata (2006), sendo vocabulário e estratégia de consulta ao dicionário, ensino de gramática e avaliação, respectivamente, os temas contemplados nestas pesquisas. 
${ }^{4}$ Destacamos também o estudo de Geraldini (1995), a qual se ocupou da investigação de crenças sobre leitura em língua francesa.

${ }^{5}$ Acrescentamos aqui o trabalho de Rauber e Gil (2005) sobre correção de erros gramaticais.

${ }^{6} \mathrm{O}$ conceito de investimento, cunhado por Pierce (1995), tenta capturar a relação entre o aprendiz de línguas e o contexto. Assim, esse aprendiz não é entendido como um ser ahistórico e unidimensional, mas como tendo uma história social complexa e múltiplos desejos.

${ }^{7}$ Por pressão ideológica, a professora refere-se à imposição do "sonho americano" ao povo norte-americano e aos demais povos.

\section{Referências}

ARAÚJO, D. R. Crenças de professores de inglês de escolas públicas sobre o papel do bom aprendiz: um estudo de caso. 2004. Dissertação (Mestrado em Lingüística Aplicada) - Faculdade de Letras, Universidade Federal de Minas Gerais, Belo Horizonte, 2004.

BARATA, M. C. C. M. O ensino de cultura e a aquisição de uma língua estrangeira. 1999. Dissertação (Mestrado em Lingüística) - Instituto de Letras e Lingüística, Universidade Federal de Uberlândia, Uberlândia, 1999.

BARATA, M. C. C. M. Crenças sobre avaliação em língua inglesa: um estudo de caso a partir das metáforas no discurso de professores em formação. 2006. Tese (Doutorado em Lingüística Aplicada) - Faculdade de Letras, Universidade Federal de Minas Gerais, Belo Horizonte, 2006.

BARCELOS, A. M. F. Understanding teachers' and students' language learning beliefs in experience: A Deweyan approach. 2000. Tese (Doutorado em Ensino de Inglês como Segunda Língua) - The University of Alabama, Tuscaloosa, AL, USA, 2000.

BARCELOS, A. M. F. Metodologia de pesquisa das crenças sobre aprendizagem de línguas: estudo da arte. Revista Brasileira de Lingüística Aplicada, v. 1, n. 1, p. 71-92, 2001.

BARCELOS, A. M. F. Crenças sobre aprendizagem de línguas, Lingüística Aplicada e ensino de línguas. Linguagem \& Ensino, Pelotas, v. 7, n. 1, p. 123-156, 2004. 
BARCELOS, A. M. F. Cognição de professores e alunos: tendências recentes na pesquisa de crenças sobre ensino e aprendizagem de línguas. In: BARCELOS, A. M. F.; VIEIRA-ABRAHÃO, M. H. (Org.). Crenças e ensino de línguas - foco no professor, no aluno e na formação de professores. Campinas: Pontes, 2006. p. 15-42.

BARCELOS, A. M. F. Crenças sobre ensino e aprendizagem de línguas: reflexões de uma década de pesquisa no Brasil. In: ORTIZ ALVAREZ, M. L.; SILVA, K. A. (Org.). Linguística Aplicada: múltiplos olhares. Campinas: Pontes, 2007. p. 27-69.

BASSETTI, M. Z. A gramática da língua inglesa no ensino público: implementação de uma proposta pedagógica voltada para a comunicação. 2006. Dissertação (Mestrado em Estudos Linguísticos) - Instituto de Biociências, Letras e Ciências Exatas, Universidade Estadual Paulista, São José do Rio Preto, 2006.

BELAM, P. V. A interação entre as culturas de avaliar de uma professora de língua estrangeira (inglês) e de seus alunos do curso de Letras no contexto de uma universidade particular. 2004. Dissertação (Mestrado em Estudos Lingüísticos) Instituto de Biociências, Letras e Ciências Exatas, Universidade Estadual Paulista, São José do Rio Preto, 2004.

BLACKLEDGE, A. Imagining a monocultural community: racialization of cultural practice in educational discourse. Journal of Language, Identity and Education, v. 2, n. 4, p. 331-347, 2003.

BORGES. T. D. Crenças de duas professoras de inglês em pré-serviço a respeito de falantes de língua inglesa e de suas respectivas culturas. 2007. Dissertação (Mestrado em Lingüística Aplicada) - Faculdade de Letras, Universidade Federal de Minas Gerais, Belo Horizonte, 2007.

BORGES, T. D.; PAULAFERNANDES, A. E.; BARCELOS, A. M. F. Como crenças vêm sendo investigadas? Um levantamento inicial. Contexturas, v.11, p.29-48, 2007.

BRUN, M. (Re) Construção identitária no contexto da aprendizagem de línguas estrangeiras. In: MOTA, K.; SCHEYRL, D. (Org.). Recortes interculturais na sala de aula de línguas estrangeiras. Salvador: EDUFBA, 2004. p. 73-104.

CARAZZAI, M. R. P. Grammar and grammar teaching: a qualitative study of EFL teachers' beliefs and practices. 2002. Dissertação (Mestrado em Letras) Universidade Federal de Santa Catarina, Florianópolis, 2002.

CASTELLOTTI, V.; MOORE, D. Social representations of language and teaching. Council of Europe, 2002. 
COELHO, H. S. H. É possível aprender inglês em escolas públicas? Crenças de professores e alunos sobre o ensino de inglês em escolas públicas. 2005. Dissertação (Mestrado em Lingüística Aplicada) - Faculdade de Letras, Universidade Federal de Minas Gerais, Belo Horizonte, 2005.

CONCEIÇÃO, M. P. Vocabulário e consulta ao dicionário: analisando as relações entre experiências, crenças e ações na aprendizagem de LE. 2004. Tese (Doutorado em Lingüística Aplicada) - Faculdade de Letras, Universidade Federal de Minas Gerais, Belo Horizonte, 2004.

DAGENAIS, D. Accessing imagined communities through multilingualism and immersion education. Journal of Language, Identity and Education, v. 2, n. 4, p. 269-283, 2003.

FINARDI, K. Teachers'use of and beliefs on ludic language in the foreign language class. 2004. Dissertação (Mestrado em Letras) - Universidade Federal de Santa Catarina, Florianópolis, 2004.

FREEMAN, D.; JOHNSON, K. Reconceptualizing the knowledge-base of language teacher education. TESOL Quarterly, v. 32, n. 3, p. 397-417, 1998.

GERALDINI, A. F. S. Crenças na sala de aula de leitura. 1995. Dissertação (Mestrado em Lingüística Aplicada) - Pontifícia Universidade Católica de São Paulo, São Paulo, 1995.

JOHNSON, K. E. The emerging beliefs and instructional practices of pre-service English as a second language teachers. Teaching and Teacher Education, v. 10, n. 4, p. 439-452, 1994.

JAKOBOVITS, L. A. Foreign language learning - a psycholinguistic analysis of the issues. Rowley, Mass.: Newbury House Publishers, 1970.

KANNO, Y. Imagined communities, school visions, and the education of bilingual students in Japan. Journal of Language, Identity and Education, v. 2, n. 4, p. 285-300, 2003.

KANNO, Y; NORTON, B. Imagined communities and educational possibilities: introduction. Journal of Language, Identity and Education, v. 2, n. 4, p. 241-249, 2003.

LIMA, S. S. Crenças de uma professora e alunos de quinta série e suas influências no processo de ensino e aprendizagem de inglês em escola pública. 2005. Dissertação (Mestrado em Estudos Lingüísticos) - Instituto de Biociências, Letras e Ciências Exatas, Universidade Estadual Paulista, São José do Rio Preto, 2005. 
MADEIRA, F. Crenças sobre o explícito construídas pelos aprendizes de um novo idioma. 2006. Tese (Doutorado em Lingüística Aplicada) - Instituto de Estudos da Linguagem, Universidade Estadual de Campinas, Campinas, 2006.

MURPHEY, T. Language Hungry! Tokyo: MacMillan Language House, 1998.

MURPHEY, T.; JIN, C.; LI-CHI, C. Learners' constructions of identity and imagined communities. In: BENSON, P.; NUNAN, D. (Org.). Learners'stories: difference and diversity in language learning. Cambridge: Cambridge University Press, 2004. p. 93-105.

MORAES, R. N. A cultura de avaliar de uma professora no processo ensinoaprendizagem de língua estrangeira (inglês): implicações para a formação de professores. 2005. Dissertação (Mestrado em Estudos Lingüísticos) - Instituto de Biociências, Letras e Ciências Exatas, Universidade Estadual Paulista, São José do Rio Preto, 2005.

NORTON, B. Identity and language learning: gender, ethnicity and educational change. Harlow, England: Pearson Education, 2000.

NORTON, B. Non-participation, imagined communities, and the language classroom. In: BREEN, M. (Ed.). Learner contributions to language learning: new directions in research. Harlow, England: Pearson Education, 2001. p. 159-171.

NORTON, B.; KAMAL, F. The imagined communities of English language learners in a Pakistani school. Journal of Language, Identity and Education, v. 2, n. 4, p. 301-317, 2003.

PAJARES, M. F. Teachers' beliefs and educational research: cleaning up a messy construct. Review of Educational Research, v. 62, n. 3, p. 307-332, 1992.

PAVLENKO, A. "I never knew I was a bilingual": reimagining teacher identities in TESOL. Journal of Language, Identity and Education, v. 2, n. 4, p. 251-268, 2003.

PAVLENKO, A.; NORTON, B. Imagined communities, identity, and English language teaching. In: CUMMINS, J.; DAVISON, C. (Eds.). Kluwer handbook of English language teaching. Kluwer Academic Publishers (no prelo).

PEIRCE, B. N. Social identity, investment, and language learning. TESOL Quarterly, v. 29, n. 1, p. 9-31, 1995.

PITELI, M. L. A leitura em língua estrangeira em um contexto de escola pública: relação entre crenças e estratégias de aprendizagem. 2006. Dissertação (Mestrado em Estudos Lingüísticos) - Instituto de Biociências, Letras e Ciências Exatas, Universidade Estadual Paulista, São José do Rio Preto, 2006. 
RAUBER, A. S.; GIL, G. Correção de erros gramaticais de inglês-LE em ambiente comunicativo. In: GIL, G.; RAUBER, A. S.; CARAZZAI, M. R. P.; BERGSLEITHNER, J. M. (Orgs.). Pesquisa qualitativa no ensino e aprendizagem de inglês: a sala de aula e o professor de LE. Florianópolis: Editora da UFSC, 2005. p. 149-166.

SADE, L. A. Querer é poder, querer e poder, querer sem poder: a motivação para o aprendizado de inglês na escola pública sob uma perspectiva semiótica social. 2003. Dissertação (Mestrado em Lingüística Aplicada) - Faculdade de Letras, Universidade Federal de Minas Gerais, Belo Horizonte, 2003.

SILBERSTEIN, S. Teaching culture: imagined communities and national fantasies in the O. J. Simpson case. Journal of Language, Identity and Education, v. 2, n. 4, p. 319-330, 2003.

SILVA, I. M. Percepções do que seja ser um bom professor de inglês para formandos de Letras: Um estudo de caso. 2000. Dissertação (Mestrado em Lingüística Aplicada) - Faculdade de Letras, Universidade Federal de Minas Gerais, Belo Horizonte, 2000.

SILVA, S. V. Crenças relacionadas à correção de erros: Um estudo realizado com dois professores de escola pública e seus alunos. 2004. Dissertação (Mestrado em Letras e Linguiística) - Faculdade de Letras, Universidade Federal de Goiás, Goiânia, 2004.

TÍLIO, M. I. C. Cultural identity and foreign language teaching: attitudes towards English-speaking people and their culture. Revista UNIMAR, v. 3, p. 75-81, 1981.

VECHETINI, L. R. Crenças sobre o ensino de vocabulário em língua estrangeira (inglês) para alunos iniciantes. 2005. Dissertação (Mestrado em Lingüística Aplicada) - Instituto de Estudos da Linguagem, Universidade Estadual de Campinas, Campinas, 2005.

WILLIAMS, M.; BURDEN, R. L. Psychology for language teachers - a social constructivist approach. Cambridge, Cambridge University Press, 1997. 


\section{ANEXO}

\section{Questionário aberto}

\section{PARTE I:}

1. Nome completo:

2. Idade:

3. Há quanto tempo estuda inglês?

4. Há quanto tempo ensina inglês?

5. Razão de se aprender esta língua:

6. Fala outra língua? Qual (quais)? Gostaria de aprender? Quais? Por quê?

7. Outros membros da família falam outro idioma? Qual (quais)?

8. Ano de início do curso de Letras-habilitação Inglês:

9. Provável data de conclusão:

10. Por que decidiu cursar esta habilitação em Letras, tendo como língua estrangeira o inglês?

11. Você ministra aulas em outro estabelecimento além do Curso de Extensão?

\section{PARTE II:}

1. Você já visitou outros países (independentemente de a língua falada ser o inglês)? Se sim, qual (quais)?

2. Você simpatiza com algum país falante de inglês? Se sim, por qual (quais) e por quê?

3. Se respondeu sim à questão anterior, você acha que se identifica com os falantes deste(s) país(es) e com sua cultura? Se sim, por quê? Em qual (ais) aspecto(s)?

4. Você tem antipatia por algum país falante de língua inglesa? Se sim, por qual (ais) e por quê?

5. Quando você começou a estudar inglês, houve alguém que te incentivou ou recriminou? Se sim, caso se lembre, que tipo(s) de comentário(s) ocorreu(ram)? Você pensa que estes comentários influenciaram, de alguma forma, o seu aprendizado e, como consequiência, o seu ensino? Comente.

6. Que argumentos você utilizaria para convencer alguém que está em dúvida em relação a estudar inglês?

7. Você pensa que existe relação entre estudar uma língua estrangeira, no caso o inglês, e se identificar com a cultura desta língua? 